\title{
А.Э. ОГАНЕЗОВ
}

\section{СОВРЕМЕННЫЕ НАПРАВЛЕНИЯ РАЗВИТИЯ ВИЗУАЛЬНОЙ АНТРОПОЛОГИИ}

\section{Александр Эдуардович Оганезов, \\ Институт этнологии и антропологии \\ им. Н.Н. Миклухо-Маклая Российской академии наук, Этнограсрический научно-образовательный центр, аспирант \\ Ленинский просп., д. 32А, Москва, 119991, Россия \\ E-mail: alexoganezov@outlook.com}

Реферат. Визуальная антропология является современной и перспективной научной дисциплиной, привлекающей все большее количество исследователей. Междисииплинарность визуальной антропологии вовлекает в свою сферу исследователей из множества других, смежных научных дисииплин, а также представителей различных видов изобразительного искусства. Новые вызовы социально-гуманитарным дисииплинам предполагают не только модернизаиию существующей теоретико-методологической базы, но и поиск иных оригинальных концепиий для решения актуальных задач. В статье освещаются наиболее характерные для современности темь и направления исследований в рамках визуальной антропологии, такие как: антропологическое кино, антропология искусства, антропология дизайна и прикладная визуальная антропология. Проанализированы основные тенденции и направления развития научной дисциплины, а также теоретические и методологические концепиии. Определены наиболее перспективные сферы исследований визуальной антропологии в контексте социальных и гуманитарных наук. Актуальность работы заключается в структурировании исследовательской теории современной визуальной антропологии, а также в анализе актуальных проблем и методологических решений. Статья апеллирует $к$ современным теориям и базируется на актуальных концепциях развития визуальной антропологии как научной дисциплины. Использована литература современных визуальных антропологов, рассматривающих теоретические и практические аспекты научной дисииллины. Проведенное исследование позволяет утверждать, что основной особенностью современной визуальной антропологии как научной дисциплины являются ее междисииплинарность, стремление к синтезу сфер гуманитарных наук и изобразительного искусства, расширение базы визуальных источников и сфер практического применения наработанных теоретических знаний. Наиболее перспективные пути развития научной дисциплины обусловлены указанными особенностями.

Ключевые слова: визуальная антропология, этнографическое кино, социальные науки, междисциплинарность.

Для цитирования: Оганезов А.Э. Современные направления развития визуальной антропологии // Обсерватория культуры. 2018. Т. 15, № 2. С. 141147. DOI: $10.25281 / 2072-3156-2018-15-2-141-147$.

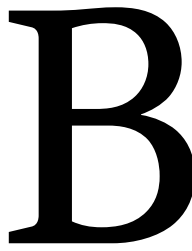

изуальная антропология на протяжении всей истории становления в качестве научной дисциплины прошла множество этапов развития, которые были обусловлены общими тенденциями в сфере гуманитарных и социальных наук, особенностями формирования визуальных искусств и кинематографа, а также различными социально-политическими событиями в жизни человечества. В настоящее время дисциплина имеет богатую историю и собственные исключительные особенности.

Можно выделить три основных направления, по которым она продолжает развиваться: 1) акаде- 
мическая визуальная антропология - теория научной дисциплины, методология, источниковедение, антропологическое кино; 2) прикладная визуальная антропология - прикладные визуальные исследования в академической и неакадемической сферах; 3) антропология искусства - изучение произведений визуального искусства с антропологической и искусствоведческой точек зрения.

Данные направления имеют характерные особенности, которые не мешают объединить их в рамках единой научной дисциплины со своей собственной теоретической базой и методологией. Далее требуется краткое описание каждого из них.

\section{АКАДЕМИЧЕСКАЯ ВИЗУАЛЬНАЯ АНТРОПОЛОГИЯ}

$\mathrm{B}$ ажнейшим аспектом визуальной антропологии является антропологическое кино. Зачастую эти два понятия даже ошибочно отождествляются. Это, с одной стороны, свидетельствует об особом месте антропологического кино в структуре научной дисциплины, а с другой - позволяет использовать его в качестве некого среза для анализа современного состояния визуальной антропологии в целом.

В современном мире, где господствует постмодернистская научно-философская концепция, не существует единого, четкого определения антропологического кино. В этом просто нет необходимости, в отличие, например, от 1970-х гг., когда существовала потребность в строгом разграничении «этнографического» и «художественного» в фильме. Данную тенденцию можно легко заметить в работе К. Хайдера «Этнографическое кино». В частности, он пишет: «В определении степени этнографичности любого фильма или при разработке проектов наиболее этнографического фильма нам нужно разобраться в качествах, одни из которых порождены этнографическими требованиями, а другие - кинематографическими. Но если эти требования вступают в конфликт, следует уступить в пользу этнографии» [1, c. 12]. Далее К. Хайдер дает, хотя и довольно расплывчатое, определение этнографическому кино: «Этнографический фильм - это фильм, в котором отражены размышления об этнографическом понимании. Что бы то ни было, это нечто большее, чем простая сумма науки и кино» [1, с. 17].

Действительно, антропологический фильм базируется на большем количестве основ, чем строго наука и кино. Антропологический фильм апеллирует к восприятию, к переживанию, к тому, что англоязычные исследователи называют емким словом «experience». Не секрет, что в эпоху постмодерна «ощущение» играет огромную роль, вытесняя собой «факт». С какими же ощущениями имеет дело антропологический фильм? Во-первых, это ощущения автора от происходящего события, которое он решил запечатлеть и исследовать; во-вторых, это ощущение «героев» фильма (тех, кто в кадре), людей, которые, собственно, и создают событие (историю), запечатленную автором; в-третьих, ощущения зрителей от увиденного на экране, т. е. от увиденного события (истории), пропущенного через призму видения (ощущения) автора фильма: «В этнографическом кино или персональной документалистике мы также познаем опыт автора по мере того, как он или она развивает повествование фильма, который мы смотрим. Иногда авторский опыт (ощущение) не выражен явно <...> а иногда выражен очень ясно» [2, p. 9].

Все это позволяет подойти к вопросу не только об авторской роли в антропологическом фильме, но и о роли антрополога в визуально-антропологическом исследовании в целом. Автор (камера) никогда не может быть полностью безучастным и дать полную объективную картину происходящего. Восприятие им окружающих событий играет огромную роль в формировании конечного продукта съемки, а то, что является важным для самого автора и что, по его мнению, составляет главные картины происходящего, в конечном итоге и становится окончательной версией фильма, воспринимаемой аудиторией. По мнению С. Макдональд, «К чему бы ни приводило происходящее с действующими лицами, мы, как зрители, должны решать, что их ощущения, транслируемые посредством кино, значат не только для них и для авторов фильма, но и что они значат для нас» [2, p. 9].

Как уже было сказано, в современной визуальной антропологии нет строгого определения понятия «антропологическое кино». Соответственно, не существует и границ, запрещающих междисциплинарное (интертекстуальное) смешение (внедрение). Во многом благодаря этому современные авторы антропологических фильмов не боятся экспериментировать и использовать различные художественные методы для более выраженного апеллирования к ощущениям. Это позволяет сфере антропологического кино не стоять на месте, а развиваться, соответствуя современным особенностям кинематогра$ф а$ и изобразительного искусства.

Классический для антропологии метод включенного наблюдения нашел свое отражение и в визуальной антропологии, а именно - в эволюции развития антропологического кино, одним из этапов которой было «наблюденческое» (observational) кино, сменившееся вскоре более новаторским подходом, обозначенным термином Д. Макдугалла «участвующее» (participatory) кино. Это два принципиально различных подхода, существующих совместно по сей день. В первом случае камера (автор) просто наблюдает за происходящим событи- 
ем и транслирует его аудитории. Во втором - камера сама становится участником изображаемого события и транслирует его изнутри, вовлекая аудиторию в происходящее. Не стоит, однако, считать, что один из методов является более прогрессивным или современным по отношению к другому. Выбор того или иного метода зависит от стоящих перед автором фильма задач.

Безусловно, частыми являются случаи, когда различные методологии смешиваются и на границах этого смешения создаются новые подходы или же первые принимают довольно причудливые формы. Так случается, например, когда герои наблюденческого фильма вдруг начинают обращать внимание на камеру и даже вступать с ней в диалог. Или же в случае использования приема, довольно часто встречающегося в антропологическом кино, когда исследователь находится в кадре и интервьюирует информанта. В этом случае исследователь способен влиять на ход событий, находясь непосредственно перед камерой.

А. Гримшоу в монографии «Этнографическое видение» проводит интересную аналогию в истории развития антропологического и художественного (игрового) кинематографа, находя очевидные параллели между двумя этими процессами. Ее основной идеей является мысль о том, что характерные особенности развития одной из сфер - антропологического или художественного кино непременно оказывают влияние и на смежное направление [3].

Работа А. Гримшоу могла бы вдохновить многих исследователей визуальной антропологии на выявление соответствующих аналогий в других сферах изобразительного искусства. Вообще, ограничение визуальной антропологии только лишь этнографическим кино представляется крайне неконструктивным. Во-первых, сама по себе дисциплина подразумевает изучение любых визуальных источников и практик, что открывает огромный простор для выбора объектов и задач перед исследователями. Во-вторых, как уже было отмечено, в реальности прослеживается тенденция к сближению современного изобразительного (визуального) искусства и визуальной антропологии. Причем сближение является обоюдным. Поэтому перед исследователями стоит задача объединения двух областей научного знания - антропологии визуального и самой практики визуального исследования, для того чтобы «теория и практика могли быть более эффективно и более продуктивно связаны» [4, p. 1].

Интересные и нетипичные вопросы о визуальном, об изображении, человеке и взаимосвязи этих объектов и понятий затрагивает известный автор антропологических фильмов Д. Макдугалл в монографии «Телесное изображение». Он считает, что изображение и вообще визуальное представляет собой особый концепт, который нельзя воспринимать и анализировать лингвистическими методами по аналогии с человеческим языком. Изображение, по мнению Д. Макдугалла, содержит в себе значительно больше информации, чем в мысли, выраженной словами или в воображаемой ассоциации, порождаемой человеческим сознанием посредством речи: «Изображения отражают мысль, они могут привести к мысли, но самое главное - они больше, чем мысль. Все мы привыкли воспринимать мысль как нечто напоминающее наш язык, как разговор с самим собой или, как это трактуется в словарях, процесс рассуждения, аргументации. Однако наши сознательные ощущения включают в себя гораздо больше, чем подобную форму мышления. Они состоят из идей, эмоций, сенсорных реакций, а также различных картин нашего воображения. То, как мы используем слова, зачастую является крайне ошибочным способом создания, использования и понимания визуальных изображений. Обращаясь к изображениям в рисунках, фотографиях и фильмах как к продукту языка или даже воспринимая эти произведения как особый язык, мы объединяем их в концепцию мысли, которая пренебрегает многими из возможных путей, согласно которым эти произведения создают наши мысли» [5, p. 1-2].

По мнению исследователя, антропологическая наука в принципе не может развиваться без использования визуального в процессе производства знания. В данном контексте способность «видеть» человека как объект исследования антропологии является базовым и ключевым аспектом в процессе познания и понимания, а отсутствие этой способности ведет к изначально ложному представлению об изучаемом: «...что делать с человеком - с воспринимающим, который думает, что принадлежит к культуре, но с точки зрения антропологии, может лишь иногда воспроизводить ее. Так как антропология развивалась из кабинетной дисциплины в учение об актуальных сообществах, то немного странно, что человек как объект изучения антропологии, продолжает оставаться невидимым для аудитории» [5, р. 213].

Кроме того, визуальная антропология, по мнению Д. Макдугалла, является не просто научной дисциплиной о человеке, которая в своем процессе познания задействует визуальные источники, а тем, что объединяет огромный пласт культуры визуального: «Здесь необходимо настоять, что визуальная антропология имеет дело не с визуальным как таковым, а с целым спектром культурно изменяемых отношений, опутанных и закодированных визуальным. Антропология может как прочитать эти отношения в визуальном, так и использовать визуальное для создания работ, способных дать более широкое представление о том, как культура проникает и моделирует социальный опыт» [5, р. 221-222]. 
В итоге Д. Макдугалл дает оптимистичную и высокую оценку визуальной антропологии в рамках социальных наук вообще и визуальных исследований в частности.

Однако, как уже было сказано ранее, не следует ошибочно отождествлять антропологическое кино и визуальную антропологию в целом. Исследователи в рамках данной сферы используют в работе различные визуальные источники: живопись, фотографию, архитектуру и многое другое.

\section{ПРИКЛАДНАЯ ВИЗУАЛЬНАЯ АНТРОПОЛОГИЯ}

$\Pi$ рикладную и академическую визуальную антропологию не следует воспринимать как два принципиально разных понятия. Их цели и задачи, а также методология во многом очень схожи, хотя и определяются различными факторами. Перспектива взаимодействия этих двух направлений дисциплины представляется весьма плодотворной: академическая сфера предоставляет мощную теоретическую и методологическую базу, в то время как прикладная сфера на конкретных примерах демонстрирует применение этой базы, ее преимущества и недостатки при реализации различных проектов.

Процесс синтеза теоретических знаний с практиками неакадемического применения визуального исследования можно проследить на опыте антрополога С. Пинк, которая посвятила несколько разделов его описанию в монографии «Будущее визуальной антропологии». Вот что она пишет: «В 1999 году я осуществила проект по прикладной визуальной антропологии для Unilever Research. Это был коммерческий проект, сфокусированный на исследовании отношений между понятиями “уборка, дом и стиль жизни”. Для его реализации был необходим мой опыт антрополога Англии и Испании, гендерных исследований и визуальной антропологии. Исследование также включало три направления моего академического интереса - гендер, дом и эмпирическое восприятие» [6, p. 59].

Свою работу С. Пинк основывала на интервьюировании информантов, видеосъемке их домов и квартир, предоставляя им полную свободу выражения собственной индивидуальности. «Чтобы представить свою идентичность и свой дом, информанты использовали различные формы ощущений: музыку, изображения, запах и прикосновение. Это не воспроизводило ни их повседневной жизни, ни роли звука, запаха, прикосновения или зрительного в ней. Тем не менее, видеотур побуждал информантов привлечь реквизит и ощущения, а также, используя эмпирические медиа, выразить свой образ жизни в своем доме посредством знания, которое было ни исключительно визуальным, ни вербальным» [6, p. 63].

Говоря о возможной сфере применения прикладной визуальной антропологии, а также о развитии научной дисциплины в целом, С. Пинк отмечает, что неакадемический интерес к различным формам «этнографии» как способу понимания ощущений других совмещается с доступностью и возможностями простых в использовании цифровых визуальных технологий. Это делает визуальную методологию основной в прикладных исследованиях. Перспективы же прикладной визуальной антропологии, предполагающие большую долю вовлечения в антропологию в XXI в., обусловливаются несколькими факторами. Во-первых, уникальным потенциалом социального внедрения «визуального» [6, p. 82]. Практики визуальной, а также классической антропологии все чаще включают визуальные источники, методологии и способы презентации научных исследований и проектов. Визуальное воздействие, сильнее влияющее на восприятие и память, имеет преимущества в сравнении с другими видами передачи информации и охватывает более массовую аудиторию. Во-вторых, прикладная визуальная антропология может существенно дополнить теорию как визуальной, так и классической антропологии. И наконец, она способна внести вклад в междисциплинарные исследования.

Говоря о публичной роли и ответственности антропологии, С. Пинк поднимает интересный вопрос о том, как антропологическое кино способно предлагать варианты решения актуальных социальных проблем, акцентировать внимание на тех сторонах общественных коммуникаций, которые остаются без внимания СМИ. В данном контексте у визуальной антропологии открывается новая сторона, которая позволяет говорить о ней не только как о научной дисциплине, но и как о методе воздействия на социальные отношения.

Отдельной ветвью прикладной визуальной антропологии можно назвать довольно современное и набирающее популярность направление - визуальная антропология дизайна и городского пространства. Данное направление является весьма перспективным вектором развития научной дисциплины в рамках визуальной антропологии. Подобный поворот в сфере научных интересов визуальной антропологии вполне объясним. Во-первых, современные процессы глобализации и урбанизации ставят перед представителями социальных наук новые актуальные задачи и вопрос об антропологии города находится в их числе. Во-вторых, изменяется сама концепция города и обустройства городского пространства. Город перестает быть попросту местом скопления капитала и центром сосредоточения большого количества рабочих мест, теперь он переориентируется на индивидуальность, на своего 
жителя, представителя различных возрастных поколений, культур, этносов. Новое осмысление города и обустройства городского пространства начинается с аналогичного переосмысления собственного жилища, в связи с чем видна параллель между антропологией дизайна, архитектуры и города. Также подобные вопросы особенно актуальны в современном мире с присущими ему процессами этнических миграций, смешения культур и тенденции к стиранию различного рода границ. В 2017 г. С. Пинк в соавторстве с другими исследователями опубликовала новую книгу под названием «Making homes: ethnography and design», в которой содержатся исследования по визуальной антропологии дизайна и городского пространства [7].

Таким образом, можно сказать, что неакадемическое прикладное исследование является «неакадемическим» лишь условно, так как исследователь в любом случае вносит в него элементы научности и одновременно обогащает в процессе работы теоретическую базу и методологию академической науки.

\section{АНТРОПОЛОГИЯ ИСКУССТВА}

$\mathrm{O}$ тносительно новым в визуальной антропологии является направление антропологии искусства - субдисциплина, возникшая на рубеже визуальной антропологии и изобразительного (визуального) искусства, вследствие их взаимного притяжения друг к другу. Данное направление в развитии визуальной антропологии представляется весьма перспективным и способным привлечь к себе большое внимание как антропологов, так и специалистов в сфере искусства.

Интересным примером может послужить опыт художницы и антрополога А. Раветц, описанный ею в статье «Новости из дома: Размышления об изобразительном искусстве и антропологии». Создавая этнографический фильм, она поставила перед собой задачу совместить в нем художественное и антропологическое. В фильме изначально задумывалось представить два различных сюжета, разворачивающихся в разных пространствах в здании совета в общественном центре в месте, известном как Дайнли, и на ферме семьи Брэйсвелл. Автор хотела, с одной стороны, используя видеокамеру, «нарисовать» пейзажи фермы и картины усадьбы, а с другой - показать жизнь местных людей. Однако в итоге фильм был создан только лишь из сюжета, снятого на ферме, который получил название «Брэйсвеллы» («The Bracewells», 2001) [8]. Анализируя результаты собственного эксперимента, она пришла к тому, что «дальнейшее развитие визуальной антропологии предполагает увеличение роли визуального... Практикам визуальной антропологии необходимо больше вовлекаться в художественную деятельность, которая обычно находилась вне сферы дисциплины. На протяжении долгого времени визуальная антропология была сфокусирована главным образом на определенном виде документального кино. Новые пересечения прикладного искусства и других визуальных практик предлагают обширный простор для развития антропологического воображения» [4, p. 78].

По мнению А. Раветц, визуальная антропология и современное изобразительное искусство имеют много общих аспектов и должны продолжать сближаться в теории и на практике, так как сфера изобразительного искусства способна значительно расширить сферу деятельности и применения визуальной антропологии: «Методологии обеих дисциплин включают в себя причудливое сопоставление элементов своего и чужого. Проект визуальной антропологии, безусловно, расширяет эти границы. Смелая игра визуального в антропологии идет рука об руку с переосмыслением роли воображения в рамках дисциплины» [4, p. 78].

Опыт антропологического кино А. Раветц интересен тем, что сам автор в первую очередь является художником, представителем современного прикладного искусства, и ее интерес к антропологии был обусловлен стремлением современного искусства к изображению, а также к использованию человека в качестве неотъемлемой части готового произведения искусства. Кино А. Раветц нельзя назвать ни прикладным, ни академическим. Это опыт слияния визуальной антропологии и современного изобразительного искусства - «человеческого» и «искусственного» в одном произведении, которое само по себе является самостоятельным продуктом нового направления как в антропологии, так и в искусстве. Подобный подход позволяет по-новому взглянуть на источники и методологии, используемые в визуально-антропологическом исследовании. Взаимное встречное движение визуальной антропологии и изобразительного искусства позволяет расширить сферы внедрения и распространения обеих дисциплин.

Из всего этого следует, что современная эпоха с ее стремлением к глобализации и стиранию границ ведет не только к развитию междисциплинарности в науке, но и к междисциплинарности в более широком смысле, как видно из приведенного примера.

$$
* * *
$$

Социальные науки в наши дни все больше включаются в повседневную жизнь и увеличивают свое влияние на человеческое общество. В этом контексте визуальная антропология не является исключением. Высокая степень междисциплинарности, а также применение в своей деятельности визуальных источников и методологий позволяют данной научной дисциплине активнее внедряться в различ- 
ные аспекты жизнедеятельности и популяризировать сферу своих исследований ${ }^{1}$.

Визуальная антропология продолжает развиваться как самостоятельная научная дисциплина и оригинальная сфера научного знания, обладающая огромным потенциалом. В современных условиях развития и популяризации Интернета антропологи имеют возможность не только получать доступ к огромному количеству визуальных источников, но и выстраивать коммуникацию внутри своего сообщества. Различные социальные сети, а также фото- и видеохостинги позволяют хранить и делиться своими проектами и работами, привлекать аудиторию для дискуссий. Развитию коммуникации внутри научного сообщества способствует также наличие и увеличение числа электронных библиотек, которые представляют исследователям возможность ознакомиться с работами своих коллег из разных стран.

Коммуникация в научной сфере является крайне важным аспектом для существования визуальной антропологии в России. К сожалению, в настоящее время в сфере российского высшего образования не существует школы визуальной антропологии, а ее становление в науке основывается на энтузиазме узкого круга людей - специалистов в области антро-

${ }^{1}$ Подробнее о междисциплинарности в гуманитарном познании см.: [9]. (Примеч. ред.) пологии, кинематографа и просто неравнодушных. Однако все эти недостатки современного состояния научной дисциплины в нашей стране открывают новые пути и направления для исследователей в их профессиональной деятельности.

\section{Список источников}

1. Хайдер К. Этнографическое кино. Москва, 2000. 187 с.

2. MacDonald S. American ethnographic film and personal documentary. Berkeley, 2013. 415 p.

3. Grimshaw A. The ethnographer's eye. Cambridge, 2001. $222 \mathrm{p}$.

4. Grimshaw A., Ravetz A. Visualizing anthropology. Bristol, 2005. 167 p.

5. MacDougall D. The corporeal image : film, ethnography and the senses. Princeton, 2006. 312 p.

6. Pink S. Future of visual anthropology. Abingdon, 2006. $166 \mathrm{p}$.

7. Pink S., Leder Mackley K., Morosanu R., Mitchell V., Bhamra T. Making homes: ethnography and design. London, 2017. $176 \mathrm{p}$.

8. The Bracewells : film [Электронный ресурс]. URL: https://vimeo.com/33465829 (дата обращения: 13.02.2018).

9. Волкова Н.А., Катаева О.В., Ходанович М.А. Междисциплинарность в гуманитарном познании // Обсерватория культуры. 2018. T. 15, № 1 . С. $32-38$. DOI : 10.25281/2072-3156-2018-15-1-32-38.

\section{Contemporary Ways of Development in Visual Anthropology}

\section{Aleksandr E. Oganezov}

N.N. Miklouho-Maclay Institute of Ethnology and Anthropology of the Russian Academy of Sciences, 32A, Leninsky Av., Moscow, 119991, Russia

E-mail: alexoganezov@outlook.com

Abstract. Visual anthropology is a modern and perspec-
tive scientific discipline, involving a big number of re-
searchers. Interdisciplinarity of visual anthropology
involves the researchers from other different adjacent sci-
entific disciplines and agents from different kinds of fine
arts. New challenges for modern social and humanitar-
ian sciences expect not only modernization of existing
theoretical and methodological basis, but also a search
of different new concepts for solving actual problems.
The article presents specific themes of research in mod-
ern visual anthropology, such as anthropological cin-
ema, anthropology of art, anthropology of design, ap- plied visual anthropology. The article analyzes the main features and ways of development of scientific discipline, as well as theoretical and methodological conceptions. The most perspective ways of visual anthropological research among the social and humanitarian sciences are pointed out. The relevance of the article is in the structuring of the modern visual anthropology research theory and the analysis of the current ways of methodological practices and actual problems. The article appeals to modern theories and is based on relevant conceptions of development in visual anthropology as a scientific discipline. The article includes the literature of modern visual anthropologists, studying theoretical and practical aspects of scientific discipline.

The research allows to confirm that the main specific feature of modern visual anthropology is interdisciplinarity, tendency for the collaboration between humanities and fine arts, expansion of visual sources and spheres of practical use. The most perspective ways of scientific discipline development are conditioned by these specifics.

Key words: visual anthropology, ethnographic cinema, social sciences, interdisciplinarity. 
Citation: Oganezov A.E. Contemporary Ways of Development in Visual Anthropology, Observatory of Culture, 2018, vol. 15, no. 2, pp. 141-147. DOI: $10.25281 / 2072-$ 3156-2018-15-2-141-147.

\section{References}

1. Heider K. Ethnographic Film. Moscow, 2000, 187 p. (in Russ.).

2. MacDonald S. American Ethnographic Film and Personal Documentary. Berkeley, 2013, 415 p.

3. Grimshaw A. The Ethnographer's Eye. Cambridge, 2001, $222 \mathrm{p}$.

4. Grimshaw A., Ravetz A. Visualizing Anthropology. Bristol, 2005, $167 \mathrm{p}$.
5. MacDougall D. The Corporeal Image: Film, Ethnography and the Senses. Princeton, 2006, $312 \mathrm{p}$.

6. Pink S. Future of Visual Anthropology. Abingdon, 2006, $166 \mathrm{p}$.

7. Pink S., Leder Mackley K., Morosanu R., Mitchell V., Bhamra T. Making Homes: Ethnography and Design. London, 2017, $176 \mathrm{p}$.

8. The Bracewells: film. Available at: https://vimeo. com/33465829 (accessed 13.02.2018).

9. Volkova N.A., Kataeva O.V., Khodanovich M.A. Interdisciplinarity in the Humanitarian Knowledge, Observatory of Culture, 2018, vol. 15, no. 1, pp. 3238. DOI: $10.25281 / 2072-3156-2018-15-1-32-38$ (in Russ.).

\section{ФЕНОМЕН ТВОРЧЕСКОЙ ЛИЧНОСТИ В КУЛЬТУРЕ: ФАТЮЩЕНКОВСКИЕ ЧТЕНИЯ}

Целью конференции является постижение, сохранение и развитие личностного творческого начала в культуре. Конференция ориентируется на комплексное исследование филососрских, религиозных, историко-культурных, фольклорных, литературных, лингвистических, искусствоведческих аспектов творчества как культурообразующего процесса, лежащего в основе созидательной деятельности человека; на сохранение памяти о творческих личностях, чья преобразовательная деятельность внесла значительный вклад в национальную и мировую культуру; на изучение образа творческой личности в художественной культуре.

В рамках конфреренции предполагается обсуждение следующих аспектов:

1. Историко-культурное наследие и духовные ценности России.

2. Творческие традиции национальной культуры и фольклор.

3. Традиция и творчество в культурах коренных народов. Памяти А.В. Ващенко.

4. Историческая память как коллективный текст.

5. Текст как сценарий идентичности.

6. Человек в зеркале текста: феномен автобиографизма в культуре.

7. Педагогика как творчество: история и современность.

8. Musurgia universalis: проблемы творчества в музыкальных культурах мира.

\section{Оргкомитет конференции:}

119192, Россия, Москва,

Факультет иностранных языков и регионоведения МГУ им. М.В. Ломоносова,

Ленинские горы, д. 1, стр. 13-14 (IV гуманитарный корпус)

Касредра сравнительного изучения национальных литератур и культур, ауд. 335 